University of Zurich

Department of Economics

Working Paper Series

ISSN 1664-7041 (print)

ISSN 1664-705X (online)

Working Paper No. 157

\title{
The Value of Top-Down Communication for Organizational Performance
}

Leif Brandes and Donja Darai

May 2014 


\title{
The Value of Top-Down Communication for Organizational Performance*
}

\author{
Leif Brandes ${ }^{\dagger} \quad$ Donja Darai ${ }^{\ddagger}$
}

May 22, 2014

\begin{abstract}
We design a laboratory experiment to identify causal performance effects of top-down communication between managers and their subordinates. Our focus lies on communication that resolves uncertainty about the work environment but does not provide task-specific knowledge. Recent articles in the business press report a lack of such communication in real-world organizations and associate it with reduced organizational performance. Our results confirm this observation. We find that top-down communication is a profitable way for managers to increase employee performance in the presence of uncertainty. Specifically, we show that non-communication is the worst option for managers. However, 50 percent of our experimental managers use top-down communication too restrictively. Overall, managers forego 30 percent of their potential profits through non-communication. We show that organizations can overcome this problem by adopting automated information procedures, which are equally effective.
\end{abstract}

Keywords: communication procedures, non-instrumental-information, employee motivation

JEL classification: C92, D23, D83, M54

${ }^{*}$ The authors thank Björn Bartling, Ernst Fehr, Holger Herz, Armin Schmutzler, Frédéric Schneider, Daniel Schunk, Roberto Weber, the seminar participants at the University of Zurich, and the conference participants at the International Meeting on Experimental and Behavioral Economics 2012 in Castellón, Mainz Workshop in Behavioral Economics 2012, Economic Science Association European Conference 2012 in Cologne, Experimental Science Association World Meetings 2013 in Zurich, for helpful discussions and suggestions. Financial support of the Forschungskredit of the University of Zurich is gratefully acknowledged.

${ }^{\dagger}$ Warwick Business School, University of Warwick, leif.brandes@wbs.ac.uk

${ }^{\ddagger}$ Department of Economics, University of Zurich, donja.darai@econ.uzh.ch. 
"Communicate everything you can to your associates. The more they know, the more they care."

Sam Walton, founder of Wal-Mart

\section{Introduction}

The functioning and success of organizations requires that all members have timely access to information that influences their behavior. Such information can be manifold, but often originates on a higher hierarchy level, which implies that organizations need to install appropriate communication procedures to assure sufficient information flow across hierarchical levels and business units. A widely employed communication procedure is top-down, written communication - e.g., emails or memos - that managers direct to their subordinate employees. However, when thinking about installing this procedure, organizations face two important questions: First, will managers decide correctly about what kind of information to communicate to their subordinate employees, and second, how do managers' communication decisions influence employee productivity? The goal of this paper is to answer both questions to determine the value of top-down communication for organizational performance.

According to standard economic theory, communication decisions for managers are relatively straightforward: managers should only engage in top-down communication of information that is instrumental in nature. Instrumental information is important, because it comprises task-specific knowledge that is necessary for the employee to complete her work task. A key implication of this perspective is that communication of any other information (e.g., changes in a company's vision or goals) is irrelevant for employee performance. Thus, it is optimal for managers to withhold such information from employees to reduce communication costs. 
A number of recent articles in the business press question the validity of this perspective and suggest that the concept of relevant information in organizational contexts may be more complex. Specifically, these articles describe a lack of top-down communication in connection with changes in corporate policies, goals, visions, or financial results (e.g., CNN-Money, 2013; WSJ, 2012), and relate it to frustration, demotivation and reduced productivity among employees. Organizations should be concerned about these observations because they suggest that managers frequently misjudge the relevance and motivational power of information for subordinate employees, implying that top-down communication is often ineffective. A key challenge is therefore to provide managers with a more extensive guidance on what type of information they need to communicate to subordinates.

In contrast to standard economic theory, social psychology emphasizes that managers also need to communicate non-instrumental information if it reduces employee uncertainty. The reason is that the communication of such information improves employees' perception of organizational justice, which increases their productivity and motivation. ${ }^{1}$ Accordingly, many employees perceive their manager as unjust when she exposes them to uncertainty by withholding information about developments in the work environment (Bies, 2001), and might respond with reduced work motivation and productivity (e.g., Reb, Goldman, Kray, and Cropanzano, 2006; Ambrose, Seabright, and Schminke, 2002; Sklarlicki and Folger, 1997). Managers should therefore resolve employee uncertainty by communicating "everything they can" to avoid that employees feel less valuable and become less committed to the firm (BusinessWeek, 2000; Keye and Jordan-Evans, 2008). Overall, social psychology provides a rationale for the adverse employee reactions in the aforementioned business articles, and suggests how to avoid them.

This paper employs a laboratory experiment to test for the causal relationship between

\footnotetext{
${ }^{1}$ The literature on organizational justice distinguishes between interactional, procedural, and distributive justice, (e.g., Cohen-Charash and Spector, 2001), and views the communication of non-instrumental information as an aspect of interactional justice (Bies and Moag, 1986; Bies, 1987; Cropanzano and Greenberg, 1997).
} 
top-down communication and employee performance. We design a hierarchical two-stage game, in which an employee faces uncertainty about his work environment while engaging in a productive activity for his manager. Specifically, an employee faces uncertainty about his exogenously assigned fixed wage level, which can either be high or low. ${ }^{2}$ In the first stage, managers have the possibility to resolve uncertainty for the employee via a costly, fixedform message. In the second stage, the employee observes the manager's communication decision, and then chooses productive effort. Overall, this design affords us with a high degree of control over who can initiate communication, its form and content, and how employees can respond to it.

Our main finding is that top-down communication has a causal influence on employee performance: relative to non-communication, employee effort is 180 percent higher after good news (the high wage) and 47 percent higher after bad news (the low wage). These changes in performance are sufficiently high to compensate managers for incurred communication costs. That is, top-down communication provides an effective, profitable motivation device for managers, implying that managers should indeed communicate "everything they can" (i.e., low and high wage levels) to subordinates. However, we find that only 50 percent of managers do so. The other 50 percent of managers are either too restrictively in their use of communication (40 percent only communicate either good or bad news), or abstain from communication altogether (10 percent). We find that non-communication leads to substantial profit losses of 30 percent for organizations.

We also show that the changes in employee performance after top-down communication cannot be attributed to positive intention-based reciprocity between employees and managers alone, because automated information procedures are equally effective. Instead,

\footnotetext{
${ }^{2}$ We use the fixed wage level as the matter about which there is uncertainty in order to capture the discrepancy in the understanding of relevant information between social-psychological and standard economic theory. That is, resolving uncertainty about the fixed wage should increase employee motivation and performance from the perspective of social psychology, but not from the perspective of standard economic theory.
} 
we show that these changes are primarily due to the resolution of employee uncertainty, because employee performance tends to be smaller after communication in an environment without uncertainty. Importantly, our experimental design allows us to rule out a number of alternative explanations, such as paid attention by supervisors, reduced social distance through communication, inequality aversion of employees, or concerns for social esteem. Turning to the decision making of managers, we do not find evidence for the idea that managers view communication as a behavioral norm, because managers stop communicating in a condition, in which a random draw determines employee effort exogenously.

Our findings represent first experimental evidence on the value of top-down communication for organizational performance, and show that this value can be substantial when communication resolves uncertainty. In focussing on the motivational role of non-instrumental information in strategic interactions, we contribute to a small economic literature that shows people's positive willingness to pay for non-instrumental information (Eliaz and Schotter, 2007, 2010). In addition, we extend the behavioral economics literature on employment relations. Several studies in this area show that organizations can use nonmonetary components, such as respect (Ellingsen and Johannesson, 2007), attention (Dur, 2009), decision authority (Charness, Cobo-Reyes, Jiménez, Lacomba, and Lagos, 2012; Fehr, Herz, and Wilkening, 2013), or the time and effort that employers put into the presentation of the monetary gift (Kube, Maréchal, and Puppe, 2012) to influence employee performance. We document that top-down communication of uncertainty-resolving information represents another such non-monetary component.

The findings of our study also inform the literature on organizational economics (e.g., Garicano, 2000; Bloom, Garicano, Sadun, and Van Reenen, 2011). An important topic in this literature is to analyze organizational design, for instance, by determining the optimal breadth of hierarchical levels, i.e., the number of subordinates about which a manager has authority. Studies in this field assign managers an important role as "processors or genera- 
tors of information which could be used by others in making decisions" (Mookherjee, 2013, p. 676), which implies that breadth is limited by managers' time and cognitive constraints to communicate with subordinates (Garicano, 2000). Our results show that subordinates' need for communication may be higher than previously thought, and suggest that existing models - that focus on purely instrumental information - may overestimate optimal breadth. Another important area of research in this literature is to analyze the effects of managerial practices on firm performance (e.g., Gibbons and Henderson, 2013). Our findings indicate that top-down communication can be one aspect of managerial practice that helps to explain persistent productivity differences between similar enterprises.

Finally, our experimental results have clear practical implications. First, our study shows that employees' understanding of relevant information extends beyond the narrow, standard economic view, such that bad news from managers can be better than no news. Second, we show that organizations can prevent adverse performance effects in response to managers' communication failure by adopting automated information procedures. Overall, decision makers should be alarmed that our experimental evidence supports the argument in the business press that managers often misperceive the value of top-down communication, and that their lack of communication hurts organizational performance.

The rest of this paper is organized as follows. Section 2 explains our experimental design. Section 3 presents our empirical results, and Section 4 concludes.

\section{Experimental design and procedure}

Throughout our experiment, managers and employees interact with each other in a oneshot game, in which an employee chooses costly effort that benefits his manager. The game consist of two stages: In the first stage, an independent random draw determines the wage level of the employee. It is common knowledge that the realization of the wage $w$ is either 
low $\left(w_{L}=80\right)$ or high $\left(w_{H}=160\right)$, and that both outcomes are equally likely. Furthermore, it is clear that the manager is not responsible for the wage level. ${ }^{3}$ The manager observes the realized wage level and can decide if she wants to share this information with the employee by engaging in one-sided top-down communication. Such communication is costly for the manager and can only occur via a truthful fixed-form message. ${ }^{4}$ If the manager decides to communicate, denoted by $I=1$, she incurs $\operatorname{cost} c=6$, otherwise, $I=0$ and no costs arise. To cover communication costs, each manager receives an initial endowment of 10. All this is common knowledge. In the second stage, the employee observes the communication decision and needs to decide how much effort $e \in\{0, \ldots, w\}$ he wants to exert. Figure 1 depicts the game in extensive form.

Figure 1: Game in extensive form

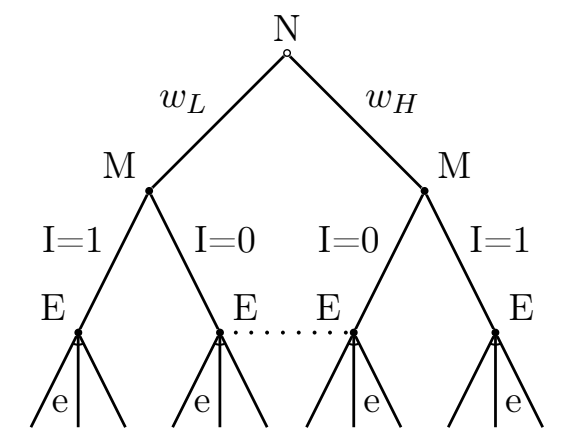

$\mathrm{N}=$ Nature, $\mathrm{E}=$ Employee, and $\mathrm{M}=$ Manager

\footnotetext{
${ }^{3}$ One way to think about this aspect of our design is that the fixed wage level stems from decisions made at a higher management level in the company, or from external regulations such as a minimum wage. In addition, our design has the advantage that it excludes any potential for monetary gift-exchange between managers and employees. Experimental evidence by Charness (2004) shows that randomly determined wages do not lead to considerable misattribution. We still make sure that participants in our experiment are aware of the wage determination procedure through a practice question that asks about the manager's responsibility for the wage.

${ }^{4}$ The justification for these three features is as follows. First, we design communication to be costly to mirror managers' opportunity cost of communication in real-world settings. Second, we implement communication as a written fixed-form message to keep the wording and communication styles constant across managers and wage levels. We also informed employees that managers did not have to type the message content themselves. In consequence, communication cannot induce employee responses to realeffort from managers. Third, we restrict managers to truth-telling in our game, since we are not interested in studying managers' use of communication to outwit subordinates.
} 
The associated expected payoffs for employees and managers, denoted by $\Pi_{E}$ and $\Pi_{M}$ respectively, take the form:

$$
\begin{aligned}
\Pi_{E}(e) & =\frac{1}{2} 80+\frac{1}{2} 160-e \\
\Pi_{M}(I) & =10+2 e-6 I .
\end{aligned}
$$

From the payoff functions it is clear that effort is productive, because its marginal return for the manager exceeds its marginal cost for the employee. ${ }^{5}$ Standard economic theory predicts that, in equilibrium, the employee will always choose zero effort, and that the manager will never inform the employee about his wage level. ${ }^{6}$

\subsection{Experimental conditions}

The previously described game represents our baseline condition, which we call Manager. In addition, we construct three variants of the game, depicted in Figure 2.

Figure 2: Alternative conditions in extensive form

(a) Automated

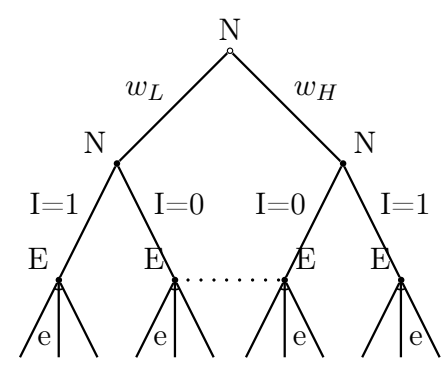

(b) Automated \& manager

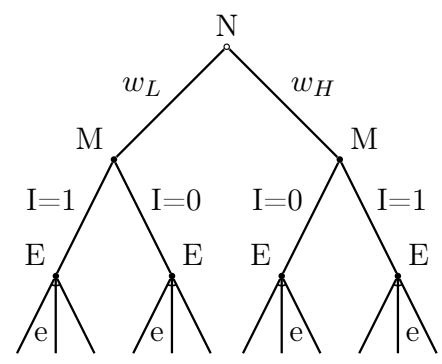

(c) Manager $w / o$ response

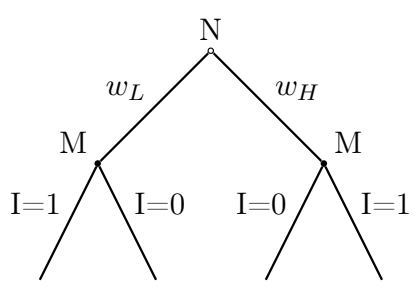

$\mathrm{N}$ draws $e$ from $\{0,5,10,25,50\}$

$$
\mathrm{N}=\text { Nature, } \mathrm{E}=\text { Employee, and } \mathrm{M}=\text { Manager }
$$

\footnotetext{
${ }^{5}$ Overall, this game can also be interpreted as an extended dictator game with a positive efficiency parameter and a recipient's endowment. Falk and Kosfeld (2006) use a similar game to model managerworker relationships.

${ }^{6}$ The fact that communication has no value in this game distinguishes our study from the literature on sender-receiver games and the concept of strategic information transmission as introduced by Crawford and Sobel (1982) and developed further by many others (e.g., Potters, 1992; Olszewski, 2004; Dewatripont and Tirole, 2005).
} 
Panel (a) shows the first variant, in which employees have an external source of information, while the manager cannot initiate top-down communication. We call this the Automated condition, because a coin flip decides whether the employee knows about his wage level prior to effort choice. It is important that the message does not reference the manager as sender, and that the manager does not incur any communications costs. In the second variant, depicted in Panel (b), the employee also learns about the realization of the wage level, while the manager can initiate top-down communication. We call this the Automated $\&$ manager condition, because top-down communication from the manager merely repeats information that the employee already holds. This is common knowledge. In the third variant, depicted in Panel (c), we introduce an external random device for effort selection. Specifically, for this condition $e \in\{0,5,10,25,50\}$ where each outcome is equally likely. It is important that the outcome is binding for both players' payoff. We refer to this condition as Manager without response.

\subsection{Experimental procedure}

The experiment was run in October 2011 in the experimental laboratory of a large University in Switzerland. ${ }^{7}$ In total we had 214 participants, which we randomly assigned to one of the four conditions. Each subject participated only once. Upon arrival, subjects were randomly allocated to the roles of managers and employees. Throughout the instructions that subjects received we used neutral wording and refered to managers as "player B" and employees as "player A" (see Appendix C for the complete instructions). Before the start of the experiment, subjects had to answer practice questions to make sure that they understood the experiment, and an experimenter read a summary of the instructions to the subjects to create common knowledge. After the experiment, we run a short questionnaire

\footnotetext{
${ }^{7}$ The experiment was computerized using z-Tree (Fischbacher, 2007) and the subjects were recruited using ORSEE (Greiner, 2004). Subjects were undergraduate and graduate students, excluding majors related to economics or psychology (see Table A.2 in the Appendix for summary statistics by condition).
} 
to obtain the subjects' age, gender, and motivation for their choices. In total we conducted 11 sessions, of which each lasted on average about one hour. Average earnings for subjects were around $24 \mathrm{CHF}$ (based on a conversion rate of 5 Points $=1 \mathrm{CHF}$ ). ${ }^{8}$ Table 1 provides detailed information about the number of sessions and subjects, as well as average earnings per condition. ${ }^{9}$

Table 1: Overview of experimental conditions

\begin{tabular}{lccc}
\hline condition & sessions & subjects $^{1}$ & average earnings $(\mathrm{CHF})^{2}$ \\
\hline Manager & 4 & 80 & 24.24 \\
Automated & 2 & 36 & 25.65 \\
Automated \& manager & 4 & 76 & 24.06 \\
Manager w/o response & 1 & 22 & 23.35 \\
\hline$N$ & 11 & 214 & 24.32 \\
\hline
\end{tabular}

${ }^{1}$ Half were in the role of a manager and half in the role of a worker. The number of subjects in our study reflects on our goal to have 80 subjects in the Manager and Automated $\& 3$ manager condition - initially our main conditions - and 20 to 40 subjects in the Manager w/o response and Automated condition - initially our control conditions. Analyzing the data we decided to refer to Manager as our baseline condition and use the other three as control conditions.

${ }^{2}$ Earnings include a show-up fee of CHF 10.

Independent of the condition and players' ability for active choice, managers and employees were always represented by real subjects that played the two-stage game only once. In all conditions, we used the strategy method for both players. ${ }^{10}$ Accordingly, employees had to specify their effort for both wage levels and the manager's communication decisions, while managers had to specify their communication decision for both wage levels (see the instruction in Appendix $\mathrm{C}$ for the exact implementation of the strategy method).

\footnotetext{
${ }^{8}$ Exchange of CHF to USD was approximately 1.11 at the time of the experiment.

${ }^{9}$ In addition to the sessions listed in Table 1 we run a pilot session with 20 subjects. In this session, we included the show-up fee in the wages, i.e., the worker received either 130 or 210 points and the manager received 60 points as fixed wages. Subsequently, we decided to separate the show-up fee from the wages to make it more transparent for subjects.

${ }^{10}$ The findings from Brandts and Charness (2011) suggest that treatment effects that are identified with the strategy method will also be identified using the direct response method. However, using the strategy method has the advantage that we can analyse decisions within subjects.
} 
In addition, we elicited beliefs for both players after they had made their decisions. ${ }^{11}$

\section{Results}

We structure the discussion of our experimental results as follows. First, we report evidence on employees' response to managers' communication decisions. Second, we analyze managers' use of top-down communication. Third, we combine our findings for managers and employees to determine the value of top-down communication.

\subsection{Employees' response to top-down communication}

Figure 3 shows employees' active effort choices in response to managers' communication behavior for the Manager, Automated, and Automated \& manager conditions.

Figure 3: Employees' effort choices

(a) Manager

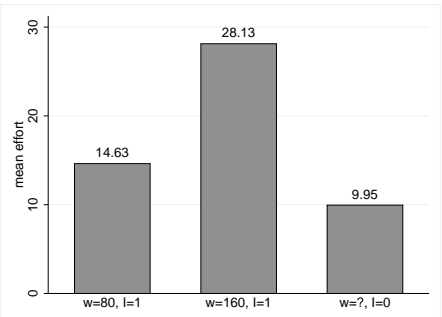

(b) Automated

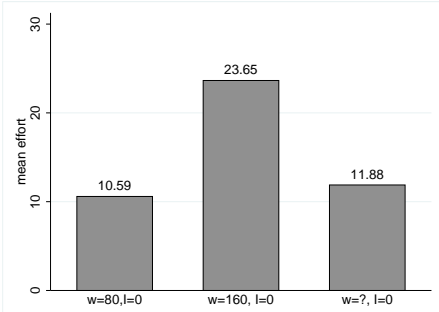

(c) Automated 85 manager

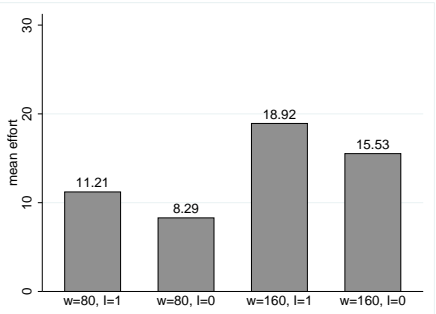

Notes: From left to right, the panels display employee effort across wage levels and communication decisions in the Manager, Automated, and Automated $\&$ manager condition, respectively. See also Table A.4 and Figures B.1 B.2, and B.3 in the Appendix for average effort choices and the distribution of effort choices in all three conditions.

Panel (a) of Figure 3 shows that employees respond positively to communication in our main condition: average effort increases from 9.95 under non-communication to 14.63

\footnotetext{
${ }^{11}$ Specifically, each employee had to answer if he believed that his manager would inform him about the low wage, about the high wage, and, for each wage level, how many of 100 managers would have informed their employees. Similarly, each manager had to answer how much effort she expected from her employee for each of the possible outcomes. To avoid any income effects we did not incentivize belief elicitation.
} 
and 28.13 in response to communication of low and high wages, respectively. That is, effort under non-communication is significantly different from effort under communication of good and bad news (two-sided Wilcoxon matched-pairs test: high wage vs. unknown wage: $\mathrm{p}<0.001$; low wage vs. unknown wage: $\mathrm{p}=0.003) .{ }^{12}$

Result 1 Top-down communication of good and bad news has a causal effect on employee performance.

In the following, we determine to which extent we can attribute this result to two specific features of our main condition: first, that managers are personally responsible for communication, and second, that communication resolves uncertainty. In the Automated and Automated $\&$ manager conditions, we remove each of these features one at a time.

In the Automated condition, the manager has no personal responsibility for communication of uncertainty-resolving information. Instead, a coin flip determines whether the employee receives information about his wage. Panel (b) of Figure 3 shows that average effort increases from 11.88 under uncertainty to 23.65 in response to information about high wages (two-sided Wilcoxon matched-pairs test: high wage vs. unknown wage: $\mathrm{p}=0.001$ ), but remains virtually identical at 10.59 in response to information about low wages (twosided Wilcoxon matched-pairs test: low wage vs. unknown wage: $\mathrm{p}=0.5165) .{ }^{13}$ That is, we observe that the positive performance effect of uncertainty-resolving information occurs only for high wages.

\footnotetext{
${ }^{12}$ The difference in employee effort across situations with good vs. bad news is also statistically significant (high wage vs. low wage: $\mathrm{p}<0.001$ ).

${ }^{13}$ Again, the difference in employee effort across situations with good vs. bad news is statistically significant (two-sided Wilcoxon matched-pairs test: high wage vs. low wage: $\mathrm{p}=0.001$ ). Note that Panel (b) of Figure 3 and the reported test statistics are based on 17 instead of 18 independent observations, since we exclude one subject that chose an effort schedule of 40, 80, and 120 points for the low, high, and unknown wage level, respectively. This pattern is exceptional, because no other subject chose such an effort increase. Table A.4 in the Appendix shows the averages using all 18 subjects and Figure B.2 in the Appendix shows the distribution of effort choices in the Automated condition. Including all subjects the same pattern of results holds.
} 
We use a censored regression model ${ }^{14}$ to examine this difference in the response patterns across both conditions in greater detail and estimate variants of the following equation

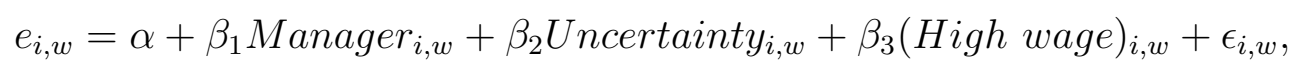

where $e_{i, w}$ denotes the effort of employee $i$ for wage scenario $w$. Manager $_{i, w}$ indicates if employee $i$ is in the Manager condition, Uncertainty Un $_{i, w}$ is an indicator variable that equals 1 if the employee does not know his wage, and $(H i g h \text { wage })_{i, w}$ indicates whether the employee knows about his high wage. To account for correlation across a subject's choices, we adjust standard errors for clustering on the subject level. Table 2 displays the associated estimation results.

In Model 1 we only include Manager $_{i, w}$ and find that effort is not significantly different across the Manager and the Automated conditions. In Model 2 we also include Uncertainty $_{i, w}$ and find that effort reduces by 11 points under uncertainty. In Model 3, we include an interaction effect of both variables, and find that effort is particularly low, if the manager is personally responsible for the employee's uncertainty. In Model 4 we include $(\text { High wage })_{i, w}$ and its interaction with Manager $_{i, w}$. Accordingly, employee's effort in response to knowing about the low wage serves as the omitted category in this model. We still find that active non-communication reduces effort significantly. In addition, this model reveals that employee effort in both conditions is 14 points higher when knowing about the high wage.

Result 2 The positive performance effect of top-down communication cannot be attributed to the manager's personal responsibility. Only if managers miss out on their opportunity for top-down communication, effort is significantly lower.

\footnotetext{
${ }^{14} \mathrm{~A}$ censored regression model allows us to deal with the non-negligible share of employees in each condition always choose zero effort: 13 percent of employees in the Manager condition and 29 percent of employees in the Automated condition choose effort levels of 0 , independent of the managers' communication decision and the wage level.
} 
Table 2: Employees' effort choices in Manager and Automated

\begin{tabular}{lcccc}
\hline & $(1)$ & $(2)$ & $(3)$ & $(4)$ \\
\hline Manager $(\mathrm{d})$ & 3.725 & 3.574 & 6.184 & 5.999 \\
& $(5.399)$ & $(5.336)$ & $(5.777)$ & $(4.249)$ \\
Uncertainty $(\mathrm{d})$ & & $-11.331^{* * *}$ & $-5.663^{* * *}$ & 1.410 \\
& & $(1.908)$ & $(1.266)$ & $(1.289)$ \\
Uncertainty ${ }^{*}$ Manager $(\mathrm{d})$ & & & $-8.021^{* * *}$ & $-7.853^{* * *}$ \\
& & & $(2.891)$ & $(2.452)$ \\
High wage $(\mathrm{d})$ & & & & $13.999^{* * *}$ \\
& & & & $(2.782)$ \\
High wage ${ }^{*}$ Manager $(\mathrm{d})$ & & & & 0.092 \\
& & & & $(3.329)$ \\
\hline F-Statistic & 0.476 & $17.640^{* * *}$ & $18.166^{* * *}$ & $21.706^{* * *}$ \\
Pseudo ${ }^{2}$ & 0.00 & 0.01 & 0.01 & 0.02 \\
N & 171 & 171 & 171 & 171 \\
Number of clusters & 57 & 57 & 57 & 57 \\
\hline
\end{tabular}

Tobit regressions report marginal effects; Standard errors in parentheses have been adjusted for clustering on the subject level. (d) for discrete change of dummy variable from 0 to $1 .{ }^{*} p<0.10,{ }^{* *} p<0.05,{ }^{* * *} p<0.01$

So far, our findings suggest that employees value the resolution of uncertainty, independent of the information procedure. To test this idea further, we now turn to the Automated 83 manager condition, in which the manager has personal responsibility for top-down communication, but employees have no uncertainty about their wages. That is, the employee already knows the realized wage when receiving the manager's message in this condition.

Panel (c) of Figure 3 shows that employees respond positively - although to a somewhat smaller extent than in the Manager condition - to top-down communication that merely repeats the employee's existing knowledge: average effort increases from 8.29 to 11.21 and from 15.53 to 18.92 in response to communication of low and high wages, respectively (twosided Wilcoxon matched-pairs test: low wage: $\mathrm{p}<0.001$; high wage: $\mathrm{p}<0.001)$. Comparing effort levels to those in the Manager conditions, we find a significant difference in effort for the high wage (two-sided, Wilcoxon test: $\mathrm{p}=0.064$ ), but not for the low wage (two-sided, 
Wilcoxon test: $\mathrm{p}=0.2296)$.

We estimate another set of censored regression models to analyze employee response patterns across both conditions. Specifically, we base our discussion on results for variants of the following equation:

$$
\begin{aligned}
e_{i, w}= & \alpha+\beta_{1} \text { Manager }_{i, w}+\beta_{2}\left(\text { No repetition }_{i, w}+\beta_{3}(\text { High wage })_{i, w}\right. \\
& +\beta_{4}\left((\text { High wage })_{i, w} \cdot \text { Manager }_{i, w}\right)+\epsilon_{i, w}
\end{aligned}
$$

where No repetition is an indicator variable that equals 1 if the manager did not communicate in the Automated \& manager condition. All other variables are defined as in equation (1).

Table 3 reports the associated estimation results when pooling the observations from the Manager and Automated $\&$ manager conditions. ${ }^{15}$ Model 1 shows that average effort in response to communication is almost 8 points higher in the Manager condition than in the Automated $\& 5$ manager condition. We also find that non-communication in the Automated 8 manager condition reduces employee effort by about 5 points. In Model 2, we include the other explanatory variables from equation (2). Accordingly, the employee's response to repeated communication about the low wage serves as the omitted category. We find that effort in response to communication tends to be higher for both wages in the Manager condition, but that this effect is more pronounced for the high wage. ${ }^{16}$

Result 3 Top-down communication in the absence of employee uncertainty has a causal effect on employee performance. The associated performance effects tend to be smaller than in response to uncertainty-resolving communication, particularly for the high wage.

\footnotetext{
${ }^{15}$ Throughout the regression analyses, we exclude effort choices under uncertainty in the Manager condition because this situation is fundamentally different from any situation in the Automated $\& 5$ manager condition.

${ }^{16}$ While the coefficient on the low wage in the manager condition (Manager in Table 3 ) is statistically insignificant, its p-value is 0.184 and thus within reasonable distance.
} 
Table 3: Employees' effort choices in Automated $\& 3$ manager vs. Manager

\begin{tabular}{lcc}
\hline & $(1)$ & $(2)$ \\
\hline Manager $(\mathrm{d})$ & $7.602^{*}$ & 4.389 \\
& $(4.296)$ & $(3.295)$ \\
No repetition $(\mathrm{d})$ & $-5.083^{* * *}$ & $-4.999^{* * *}$ \\
& $(1.033)$ & $(1.004)$ \\
High wage $(\mathrm{d})$ & & $7.929^{* * *}$ \\
& & $(1.853)$ \\
High wage* Manager $(\mathrm{d})$ & & $6.202^{* *}$ \\
& & $(2.598)$ \\
\hline F-Statistic & $13.775^{* * *}$ & $26.568^{* * *}$ \\
Pseudo $\mathrm{R}^{2}$ & 0.01 & 0.02 \\
N ${ }^{1}$ & 232 & 232 \\
Number of clusters & 78 & 78 \\
\hline
\end{tabular}

Tobit regressions report marginal effects; Standard errors in parentheses are corrected for subject clusters. (d) for discrete change of dummy variable from 0 to 1 .

1 Observations under uncertainty are excluded from the analysis. ${ }^{*} p<0.10,{ }^{* *} p<0.05,{ }^{* * *} p<0.01$

Overall, the findings from this section show that top-down communication has a positive influence on employee performance, especially in the presence of employee uncertainty. Interestingly, we also find this positive influence to be independent of the source of information. ${ }^{17}$ That is, employees seem to care mostly about that uncertainty is resolved, and not so much about how it is resolved.

\subsection{Managers' use of top-down communication}

Figure 4 shows the share of communicating managers across conditions. We observe four different communication patterns for managers: communication of only low wages, of only high wages, of both wage levels, and no communication.

\footnotetext{
${ }^{17} \mathrm{~A}$ comparison between effort choices for the Automated \&6 manager and Automated conditions shows qualitatively similar results and provides further support for this interpretation, see Table A.1 in the Appendix.
} 
Figure 4: Managers' communication decisions

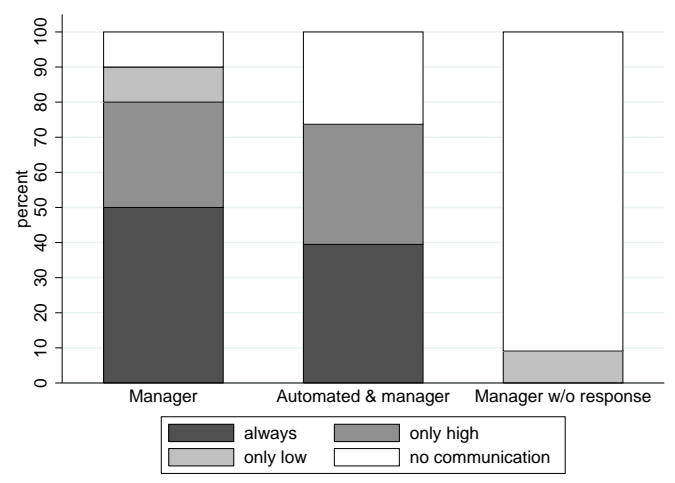

Notes: The graph shows the share of communicating managers across wage levels in the Manager, Automated $\& 3$ manager, and Manager w/o response conditions.

In the Manager condition, 50 percent of managers communicate both wages. Another 30 percent communicate only the high wage, and another 10 percent communicate only the low wage. The remaining 10 percent of managers choose not to communicate, at all. This high degree of heterogeneity suggests that managers disagree on the value of top-down communication. In the following, we determine to which extent we can attribute manager behavior to two specific features of our main condition: first, that communication can influence employee performance, and second, that communication resolves uncertainty. In the Automated $\& 5$ manager and Manager w/o response conditions, we remove each of these features one at a time.

In the Manager $w / o$ response condition, the employee has no influence on his performance. Instead, a random device selects a performance level from the set $\{0,5,10,25,50\}$ with equal probability. Figure 4 shows that this variation of the game changes manager behavior dramatically: communication breaks down almost entirely in this condition, as reflected in 91 percent of non-communicating managers. ${ }^{18}$

Result 4 Managers' use of top-down communication mirrors their attempt to influence

\footnotetext{
${ }^{18}$ These findings are based on observations from one session, in which only 1 out of 11 managers initiated top-down communication. While the number of observation is small, the evidence is highly suggestive.
} 
employee performance.

In the Automated \& $\mathcal{G}$ manager condition, top-down communication does not resolve uncertainty, but merely repeats the employee's existing knowledge. Figure 4 shows that manager behavior in this condition is very similar to our main condition with employee uncertainty. For example, 40 percent of managers still communicate both wages, while another 30 percent communicate only high wages. Based on a Kolmogorov-Smirnov test we cannot reject the equality of both distributions $(\mathrm{p}=0.779)$. Overall, this suggests that managers' use of top-down communication is not responsive to changes in employees' initial exposure to uncertainty.

In the following, we aim to understand why managers do not adapt their use of communication to the information environment. Specifically, we test if managers' communication decisions mirror their expected returns from communication, and whether these expected returns are similar across both conditions. As a first step to this end, we estimate a regression model inspired by Bellemare, Bissonnette, and Kröger (2010), in which we assume that each manager $i$ compares her expected payoffs under communication $E_{i}\left[\Pi_{M}(1)\right]$ with those under non-communication $E_{i}\left[\Pi_{M}(0)\right]$ :

$$
\begin{aligned}
& E_{i}\left[\Pi_{M}(1)\right]=\beta\left(4+2 E_{i}\left[e_{I=1}\right]\right)+\epsilon_{i, I=1} \\
& E_{i}\left[\Pi_{M}(0)\right]=\beta\left(10+2 E_{i}\left[e_{I=0}\right]\right)+\epsilon_{i, I=0} .
\end{aligned}
$$

Recall that the manager always has an endowment of 10 and communication leads to costs of 6. In addition, $E_{i}\left[e_{I=1}\right]$ and $E_{i}\left[e_{I=0}\right]$ in the equations denote manager's beliefs about employee performance in response to (non-)communication. ${ }^{19}$ To allow for suboptimal choices by managers we include two error terms $\epsilon_{i, I=0}$ and $\epsilon_{i, I=1}$. Under the assumption that both error terms follow independent Normal distributions, we can estimate the probability

\footnotetext{
${ }^{19}$ Recall that we elicited managers' beliefs after their communication decision. Table A.3 in the Appendix shows average beliefs.
} 
to communicate with a binary Probit model:

$$
\operatorname{Prob}(I=1)=\phi_{\epsilon}\left(\beta\left(2\left(E_{i}\left(e_{I=1}\right)-E_{i}\left(e_{I=0}\right)\right)-6\right)\right)
$$

Accordingly, a manager will communicate if her expected return is positive, i.e., whenever the expected performance increase is sufficiently high to cover her communication costs. Model 1 in Table 4 shows the associated results when pooling the observations from the Manager and Automated $\&$ manager conditions. We can see that expected returns are strongly predictive for managers' communication decisions.

Table 4: Managers' communication decisions and expected returns

\begin{tabular}{lcc}
\hline & $(1)$ & $(2)$ \\
& $\mathrm{I}=1$ & expected return \\
\hline Expected return & $0.004^{* * *}$ & \\
Manager $(\mathrm{d})$ & $(0.001)$ & \\
& & 0.276 \\
High wage $(\mathrm{d})$ & & $(4.486)$ \\
& & $10.947^{* * *}$ \\
High wage ${ }^{*}$ Manager $(\mathrm{d})$ & & $(3.401)$ \\
& & $27.303^{* * *}$ \\
Constant & & $(5.126)$ \\
& & 2.474 \\
\hline Wald $\chi^{2} /$ F-Statistic & $8.52^{* * *}$ & $(2.701)$ \\
Pseudo $\mathrm{R}^{2} / \mathrm{R}^{2}$ & 0.04 & $37.85^{* * *}$ \\
$\mathrm{~N}$ & 156 & 0.27 \\
Number of clusters & 78 & 156 \\
\hline Probit regressions report marginal & & 78 \\
\hline
\end{tabular}

Probit regressions report marginal effects; Robust standard errors in parentheses are corrected for subject clusters. (d) for discrete change of dummy variable from 0 to $1 .{ }^{*} p<0.10,{ }^{* *} p<0.05,{ }^{* * *} p<0.01$

In a second step, we regress the expected return on characteristics of the situation to determine if managers' beliefs are indeed similar across conditions. Model 2 in Table 4 presents estimation results from an OLS model and uses expected returns for communi- 
cation of the low wage in the Automated $\&$ manager condition as the omitted category. We find that managers do not expect higher returns from communication of uncertaintyresolving information per se, as shown in the insignificant coefficient for the condition indicator Manager. However, managers expect higher returns from communication of high wages, especially in the Manager condition.

Result 5 Managers' use of top-down communication is driven by their expectations about employee performance. Managers do not believe in the value of uncertainty resolving communication per se.

\subsection{The value of top-down communication}

Our previous results show that employees respond to any communication that resolves uncertainty about their work environment, but that managers do not correctly anticipate this response pattern. Two yet unanswered question are, if the performance increases in response to communication are sufficiently high to make top-down communication profitable, and if so, how much profit managers forego through their actual communication behavior.

Assuming that managers communicate everything they can, their profits are 3.36 for the low and 30.36 the high wage in the Manager condition. Because both wage situations are equally likely, the manager's expected profit from communication is 16.86 in this condition. In the Automated $\&$ manager condition, this value is 0.31 .

Result 6 Top-down communication of good and bad news is a profitable motivation device.

This implies that manager-employee relationships suffer from a lack of communication. A simple calculation for all managers in the Manager and Automated 86 manager conditions shows that this lack comes at substantial costs: overall, realized manager profits fall 
30 percent short of their potential profits from communicating both wages. This observation places greater weight on our finding from the Automated condition that non-personal automated information procedures are as effective as top-down communication. Accordingly, organizations may implement such procedures to avoid losses from managers' failure to communicate.

\section{Conclusion}

We use a laboratory experiment to analyze top-down communication in organizations. Our main finding is that, under employee uncertainty, top-down communication places a profitable motivational device for employee performance at managers' disposal, but that only half of all managers understand how to use this device effectively. The other half of managers incurs substantial losses through communication mistakes.

The findings from our different conditions show that this value derives primarily from the resolution of uncertainty. It is difficult to find plausible alternative interpretations for our findings. In particular, employee response to communication cannot be attributed to the motivational power of attention as modeled by Dur (2009). We are able to say this, because employee performance tends to be lower in response to communication that merely repeats information that the employee already holds. In addition, we do not find differences in employee performance in response to uncertainty-resolving information from an automated, non-personal procedure. Similarly, these observations contradict models of intention-based reciprocity (cf. Rabin, 1993; Charness and Rabin, 2002) as alternative mechanism for our findings. It is also hard to align these observations with the idea that employee performance stems from reduced social distance (e.g., Bohnet and Frey, 1999;

Mohlin and Johannesson, 2008), or improved social esteem (e.g., Andreoni and Bernheim, 2009; Ellingsen and Johannesson, 2008) through communication between managers and 
employees. Finally, our evidence contradicts models of inequity aversion (cf. Fehr and Schmidt, 1999; Bolton and Ockenfels, 2000), because we find that performance is similar across conditions with and without manager communication costs.

Overall, our simplified laboratory manager-employee relationship allows us to replicate the well-established, real-world phenomenon of a lack of top-down communication in hierarchies (WSJ, 2012; CNN-Money, 2013; BusinessWeek, 2000). A popular claim in the business press and among several practitioners is that the absence of such communication is often associated with demotivation and reduced productivity of lower-level employees. Our results represent first experimental evidence that this relationship is indeed causal, and that non-communication is particularly costly to firms when employees face uncertainty about their environment. To avoid such adverse performance effects, we show that organizations can implement automated, non-personal information procedures, which are equally effective. This insight is particularly important, as in reality, it is not uncommon for uninformed employees to eventually even leave the firm for the better. Or, as one Business Week article (BusinessWeek, 2000) put it succinctly: "Keep Employees in the Dark, and They'll Go Where It's Light." 


\section{References}

Ambrose, M. L., M. A. Seabright, and M. Schminke (2002): "Sabotage in the Workplace: The Role of Organizational Injustice," Organizational Behavior and Human Decision Processes, 89, 947-965.

Andreoni, J., And B. D. Bernheim (2009): "Social Image and the 50-50 Norm: A Theoretical and Experimental Analysis of Audience Effects," Econometrica, 77(5), 16071636.

Andreoni, J., And J. M. RaO (2011): "The Power of Asking: How Communication Affects Selfishness, Empathy, and Altruism," Journal of Public Economics, 95, 513-520.

Bellemare, C., L. Bissonnette, and S. KröGer (2010): "Bounding Preference Parameters under Different Assumptions about Beliefs: A Partial Identification Approach," Experimental Economics, 13, 334-345.

BiEs, R. J. (1987): "The Predicament of Injustice: The Management of Moral Outrage," Research in Organizational Behavior, 9, 289-319.

BiEs, R. J. (2001): "Interactional (in)justice: The sacred and the profane," in Advances in organizational justice, ed. by J. Greenberg, and R. Cropanzano, pp. 89-118. Stanford University Press.

Bies, R. J., AND J. S. MoAG (1986): "Interactional Justice: Communication Criteria of Fairness," in Research on Negotiations in Organizations, ed. by R. Lewicki, B. H. Sheppard, and M. Bazerman. JAI Press, Greenwich, CT.

Blanco, M., D. Engelmann, and H. T. Normann (2011): "A Within-Subject Analysis of Other-Regarding Preferences," Games and Economic Behavior, 72, 321-338. 
Bloom, N., L. Garicano, R. Sadun, and J. Van Reenen (2011): "The Distinct Effects of Information Technology and Communication Technology on Firm Organization," CEP Discussion Paper No. 92\%.

Bohnet, I., And B. S. Frey (1999): "Social Distance and Other-Regarding Behavior in Dictator Games: Comment," American Economic Review, 89, 335 - 339.

Bolton, G. E., And A. Ockenfels (2000): "ERC: A Theory of Equity, Reciprocity, and Competition," American Economic Review, 90(1), 166 - 193.

Brandts, J., And G. Charness (2011): "The Strategy Versus the Direct-Response Method: A First Survey of Experimental Comparisions," Experimental Economics, 14(3), 375-398.

BusinessWeek (2000): "Keep Employees in the Dark, and They'll Go Where It's Light," Business Week, January 14.

Charness, G. (2004): "Attribution and Reciprocity in an Experimental Labor Market," Journal of Labor Economics, 22, 665-688.

Charness, G., R. Cobo-Reyes, N. Jiménez, J. A. Lacomba, and F. Lagos (2012): "The hidden advantage of delegation: Pareto-improvements in a gift-exchange game," American Economic Review, 102(5), 2358-2379.

Charness, G., and M. Rabin (2002): "Understanding Social Preferences with Simple Tests," Quarterly Journal of Economics, 117(3), 817-869.

CNN-Money (2013): "Note to executives: Your employees are in the dark," CNN-Money, April 30. 
Cohen-Charash, Y., and P. E. Spector (2001): "The Role of Justice in Organizations: A Meta-Analysis," Organizational Behavior and Human Decision Processes, 86(2), 278321.

Crawford, V. P., And J. Sobel (1982): "Strategic Information Transmission," Econometrica, 50(6), 1431-1451.

Cropanzano, R., and J. Greenberg (1997): "Progress in Organizational Justice: Tunneling Through the Maze," in International Review of Industrial and Organizational Psychololy, ed. by C. L. Cooper, and I. Robertson, vol. 12, pp. 79-93. New York: John Wiley \& Sons.

Dewatripont, M., and J. Tirole (2005): "Modes of Communication," Journal of Political Economy, 113(6), 1217-1238.

Dur, R. (2009): "Gift Exchange in the Workplace: Money or Attention?," Journal of the European Economic Association, 7, 550 - 560.

ECKel, C., And H. Gintis (2010): "Blaming the messenger: Notes on the current state of experimental economics," Journal of Economic Behavior and Organization, 73, 109-119.

Eliaz, K., And A. Schotter (2007): "Experimental Testing of Intrinsic Preferences for Noninstrumental Information," American Economic Review, 97(2), 166-169.

— (2010): "Paying for Confidence: An Experimental Study of the Demand for Noninstrumental Information," Games and Economic Behavior, 70, 304-324.

Eldingsen, T., and M. Johannesson (2004): "Promises, Threats and Fairness," Economic Journal, 114(495), 397 - 420.

- (2007): "Paying Respect," Journal of Economic Perspectives, 21, 135-150. 
_ (2008): "Pride and Prejudice: The Human Side of Incentive Theory," American Economic Review, 98(3), 990-1008.

Falk, A., And M. Kosfeld (2006): "The hidden costs of control," American Economic Review, 96(5), 1611-1630.

Fehr, E., H. Herz, and T. Wilkening (2013): "The Lure of Authority: Motivation and Incentive Effects of Power," American Economic Review, 103(4), 1325-1359.

Fehr, E., And K. M. Schmidt (1999): "A Theory of Fairness, Competition, and Cooperation," Quarterly Journal of Economics, pp. 817 - 868.

FischBACHER, U. (2007): "z-Tree: Zurich toolbox for ready-made economic experiments," Experimental Economics, 10, 171-178.

Garicano, L. (2000): "Hierarchies and the Organization of Knowledge in Production," Journal of Political Economy, 108, 874-904.

Gibbons, R., And R. Henderson (2013): "What Do Managers Do?," in The Handbook of Organizational Economics, ed. by R. Gibbons, and J. Roberts, chap. 17, pp. 680-731. Princeton University Press.

Greiner, B. (2004): "An Online Recruitment System for Economic Experiments," in Forschung und wissenschaftliches Rechnen GWDG Bericht, ed. by K. Kremer, and V. Macho, vol. 63, pp. 79-93.

Keye, B., and S. Jordan-Evans (2008): Love 'em or lose 'em. Berrett-Koehler Publishers.

Kube, S., M. A. Maréchal, and C. Puppe (2012): "The Currency of Reciprocity," American Economic Review, 102(4), 1644-1662. 
Mohlin, E., And M. Johannesson (2008): "Communication: Content or Relationship?," Journal of Economic Behavior and Organization, 65, 409-419.

MookherJee, D. (2013): "Incentives in Hierarchies," in The Handbook of Organizational Economics, ed. by R. Gibbons, and J. Roberts, chap. 19, pp. 674-698. Princeton University Press.

Olszewski, W. (2004): "Informal Communication," Journal of Economic Theory, 117, 180-200.

Potters, J. (1992): "Fixed Cost Messages," Economics Letters, 38, 43-47.

Rabin, M. (1993): "Incorporating Fairness into Games Theory and Economics," American Economic Review, 83, 1281-1302.

Reb, J., B. M. Goldman, L. J. Kray, and R. Cropanzano (2006): "Different Wrongs, Different Remedies? Reactions to Organizational Remedies After Procedural and Interactional Justice," Personnel Psychology, 59, 31-64.

Rode, J. (2010): "Truth and trust in communication: Experiments on the effect of a competitive context," Games and Economic Behavior, 68, 325-338.

Sklarlicki, D. P., And R. Folger (1997): "Retaliation in the Workplace: The Roles of Distributive, Procedural, and Interactional Justice," Journal of Applied Psychology, $82,434-443$.

WSJ (2012): "What Your Employees Don't Know Will Hurt You," Wall Street Journal, February, 27. 


\section{Appendix}

\section{A Tables}

Table A.1: Employees' effort choices in Automated $\& 3$ manager vs. Automated

\begin{tabular}{lcc}
\hline & $(1)$ & $(2)$ \\
\hline Automated $(\mathrm{d})$ & 6.371 & 3.235 \\
& $(5.963)$ & $(4.524)$ \\
No repetition $(\mathrm{d})$ & $-5.099^{* * *}$ & $-5.031^{* * *}$ \\
& $(1.047)$ & $(1.024)$ \\
High wage $(\mathrm{d})$ & & $7.930^{* * *}$ \\
& & $(1.863)$ \\
High wage* Automated $(\mathrm{d})$ & & $6.117^{*}$ \\
& & $(3.346)$ \\
\hline F-Statistic & $11.936^{* * *}$ & $20.699^{* * *}$ \\
Pseudo $\mathrm{R}^{2}$ & 0.00 & 0.01 \\
N 1 & 186 & 186 \\
Number of clusters & 55 & 55 \\
\hline
\end{tabular}

Tobit regressions report marginal effects; Standard errors in parentheses are corrected for subject clusters. (d) for discrete change of dummy variable from 0 to $1 .{ }^{1}$ Observations under uncertainty are excluded from the analysis. ${ }^{*} p<0.10,{ }^{* *} p<0.05,{ }^{* * *} p<0.01$ 
Table A.2: Summary statistics

\begin{tabular}{|c|c|c|c|c|c|}
\hline Variable & Mean & Std. Dev. & Min. & Max. & $\mathbf{N}$ \\
\hline \multicolumn{6}{|l|}{ Manager } \\
\hline age & 22.7 & 6.852 & 18 & 75 & 80 \\
\hline male & 0.375 & 0.487 & 0 & 1 & 80 \\
\hline \multicolumn{6}{|c|}{ Automated $\&$ manager } \\
\hline age & 21.867 & 2.84 & 18 & 36 & 75 \\
\hline male & 0.421 & 0.497 & 0 & 1 & 76 \\
\hline \multicolumn{6}{|c|}{ Automated } \\
\hline age & 22.028 & 3.325 & 18 & 31 & 36 \\
\hline male & 0.417 & 0.5 & 0 & 1 & 36 \\
\hline \multicolumn{6}{|c|}{ Manager w/o response } \\
\hline age & 21.091 & 3.054 & 18 & 29 & 22 \\
\hline male & 0.318 & 0.477 & 0 & 1 & 22 \\
\hline
\end{tabular}

Table A.3: Managers' beliefs about employees' effort choices

\begin{tabular}{lccccc}
\hline & \multicolumn{2}{c}{ low wage } & \multicolumn{2}{c}{ high wage } & under uncertainty \\
Condition & $(\mathrm{I}=0)$ & $(\mathrm{I}=1)$ & $(\mathrm{I}=0)$ & $(\mathrm{I}=1)$ & $(\mathrm{I}=0)$ \\
\hline Manager & - & 20.88 & - & 40.00 & 16.50 \\
Automated \&6 manager & 19.53 & 23.76 & 37.95 & 47.66 & - \\
Automated & 22.39 & - & 39.33 & - & 24.33 \\
\hline
\end{tabular}

${ }^{1}$ Note that $\mathrm{E}(\mathrm{X})=120$ in the baseline model, because both endowment levels are equally likely, and information provision is not an option. 
Table A.4: Employees' effort choices across conditions and wage levels

\begin{tabular}{lccccc}
\hline & \multicolumn{2}{c}{ low wage } & \multicolumn{2}{c}{ high wage } & under uncertainty \\
Condition & $(\mathrm{I}=0)$ & $(\mathrm{I}=1)$ & $(\mathrm{I}=0)$ & $(\mathrm{I}=1)$ & $(\mathrm{I}=0)$ \\
\hline Manager ${ }^{2}$ & - & 14.63 & - & 28.13 & 9.95 \\
& & $(0.183)$ & & $(0.176)$ & $(0.083)$ \\
Automated E6 manager & 8.29 & 11.21 & 15.53 & 18.92 & - \\
& $(0.100)$ & $(0.140)$ & $(0.097)$ & $(0.120)$ & - \\
Automated & 12.22 & - & 26.78 & - & 17.89 \\
& $(0.153)$ & & $(0.167)$ & & 0.149 \\
\hline
\end{tabular}

1 Note that $\mathrm{E}(\mathrm{X})=120$ in the baseline model, because both endowment levels are equally likely, and information provision is not an option.

${ }^{2}$ Values in parentheses denote the ratio of choices to endowment.

Table A.5: Employees' beliefs about managers' communication choices

\begin{tabular}{lccc}
\hline & Manager & Automated \& manager & Manager w/o response \\
\hline No communication $^{1}$ & 11 & 11 & 7 \\
& {$[28 \%]$} & {$[29 \%]$} & {$[64 \%]$} \\
Both wage levels & 9 & 5 & 1 \\
& {$[23 \%]$} & {$[13 \%]$} & {$[9 \%]$} \\
Only low wage & 1 & 2 & 1 \\
& {$[2 \%]$} & {$[5 \%]$} & {$[9 \%]$} \\
Only high wage & 19 & 20 & 2 \\
& {$[47 \%]$} & {$[53 \%]$} & {$[18 \%]$} \\
\hline$N$ & 40 & 38 & 11 \\
\hline
\end{tabular}

${ }^{1}$ Percentage shares of subjects are given in brackets. 


\section{B Figures}

Figure B.1: Employees' effort choices in the Manager condition

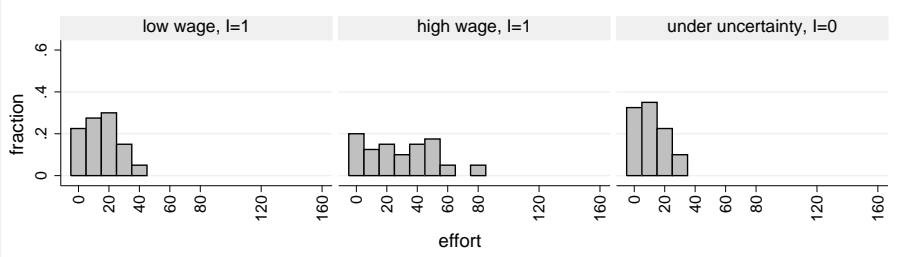

Figure B.2: Employees' effort choices in the Automated condition

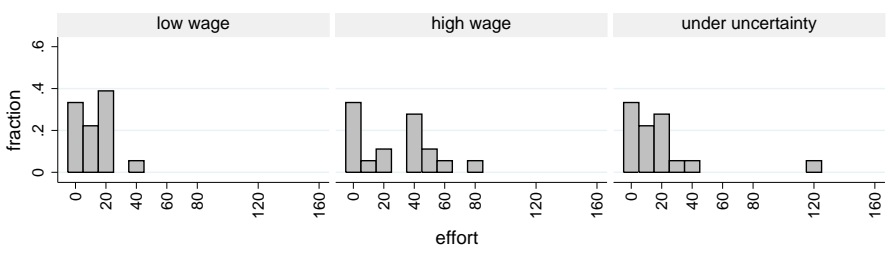

Figure B.3: Employees' effort choices in the Automated 65 manager condition

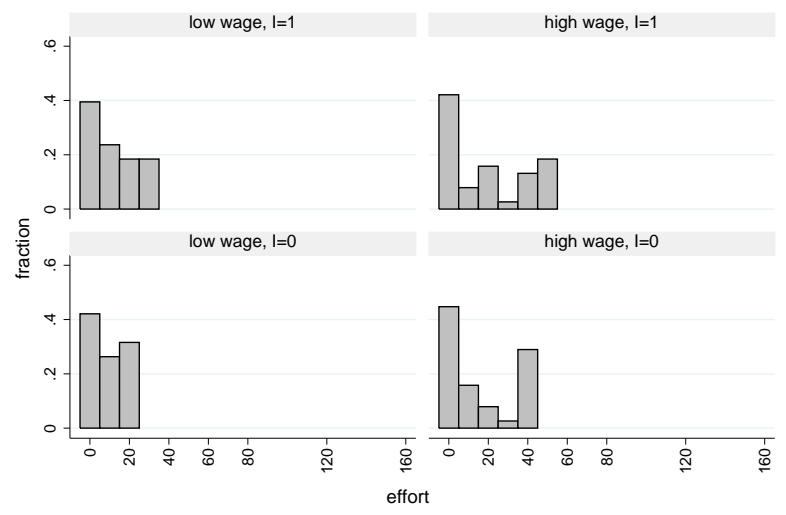




\section{Instructions}

The original instructions were in German. This Appendix reprints a translation of the instructions used in the experiment. Note that the instructions use the neutral words 'player $A$ ' and 'player B' instead of the words 'employee' and 'manager' used in the text. All text in italic is not included in the instructions used in the experiment.

Welcome to today's experiment. This experiment helps to analyze individual decision making. Your earnings in this experiment depend on your decisions, the decisions of other participants and random draws. Your income and expenses during the experiment will be calculated in terms of points. The exchange rate is $\mathbf{5}$ points $=\mathbf{C H F} \mathbf{1}$.

Independent of the decisions during the experiment, each participant receives 50 points $=\mathbf{C H F}$ 10. At the end of the experiment, your total points will be converted into CHF, and will be paid to you in cash. The payment occurs anonymously. No other participant will receive information about your payment.

Please keep in mind that you are not allowed to ask questions aloud or talk to other participants during any time of the experiment. If you do not comply with this rule, you will be immediately excluded from the experiment. If you have any questions, please raise your hand. We will come to your seat to answer your questions.

Timing of the experiment:

1. You will read these instructions and answer the control questions. The control questions shall only assert that every participant understood the instructions.

2. The experiment will be performed once.

3. After the experiment you will be requested to fill out a short survey. You will receive your payment subsequently.

Please keep in mind that all numerical examples in these instructions have been chosen randomly, and do not represent any hints or suggestions for your decision during the experiment.

\section{The Experiment}

Upon arrival, we randomly assigned the roles of "player A" and "player B" to each participant. You are player $\mathbf{A}^{20}$. At the beginning of the experiment, the computer will randomly match participants into groups of two. Each group consists of one player A and one player B. You do not have any interactions with members of other groups. No participant knows his or her matched partner. Your identity and decisions remain completely anonymous at each moment of the experiment.

\footnotetext{
${ }^{20}$ For player B, this sentence read: You are player B.
} 
At the beginning of this experiment, every player A receives either 80 or 160 points. Whether player A receives 80 or 160 points will be determined by a random draw. The probability for 80 points is $50 \%$ and the probability for 160 is also 50\%: For each group, the computer will draw a random number from the interval $[0,1]$. Each number in this interval has the same drawing probability. If the drawn number is less or equal to 0.5 , then player A receives 80 points. Otherwise player A receives 160 points.

Independent of player A's points, Player B always receives 10 points at the beginning of the experiment. In addition, player B is always truthfully informed about player A's number of points.

[Automated $\&$ manager condition:

Player A is always informed about his points. In addition, player A can be personally informed about his points by player B. Player B can only truthfully inform. By informing, player B incurs costs of 6 points.]

[Manager condition:

Player A does not know how many points he has. He can only be informed about his points by player B. Player B can only truthfully inform. By informing, player B incurs costs of 6 points.]

\section{Player A: Decision}

Each player A needs to decide how many points of his endowment to transfer to player $\mathrm{B}$ in his group. Only integer values are feasible. Player A cannot transfer more points than he actually owns. The experimentalist doubles each point that player A transfers to player B. Each point that player A transfers reduces player A's income by one point, and increases player B's income by two points. In addition, each player A needs to estimate whether player B is going to inform him personally, and how many players B out of 100 will inform.

\section{Player B: Decision}

Before player A makes his decision, player B needs to decide whether to personally inform player A about his points. Player B can only inform truthfully. By informing, player $\mathrm{B}$ incurs costs of 6 points. If player B decides to personally inform player A, player A receives the following message:

\section{Hello player A}

I just learned that the random draw is X. Thus you received Y points. I wanted to make sure that you personally receive this information from me.

Kind regards,

Player B 
If player B decides against personal information, player A receives the following message:

Player B decided not to inform you personally.

Once player $\mathrm{B}$ has made her decision, she needs to estimate the average number of points that all player A will transfer. Player A's and player B's income are calculated as follows:

Player A's income:

random draw $\leq 0.5: 80$ - (transfer to player $\mathbf{B})$

random draw >0.5: 160 - (transfer to player $\mathrm{B})$

\section{Player B's income: \\ $10+2 *($ transfer from player $A)$ - information costs}

[Examples to illustrate the calculation of both players' income (in points)]

\section{The experiment consists of two stages:}

Stage 1 Player B needs to decide whether she wants to inform player A about his points. Afterwards, player B needs to give her estimate.

Stage 2 Player A needs to decide how many points to transfer to player B. In addition, player A gives his estimates.

Following this general part of the instructions, players $A$ and $B$ received different versions of the instructions, as described in the following. 
[Player A's specific instructions in the Manager condition:

Note that you as player A need to determine your transfer choice before you know which random number has been drawn and whether player $B$ informs you personally. At the time of your decision you do not know whether

1. you received 80 points and have been informed by player B.

2. you received 160 points and have been informed by player B.

3. you are not informed about your points.

This implies that you have to make three decisions: For each of the three possible cases you have to decide how many points you want to transfer to player B.

Note that you cannot incur a loss if you choose to transfer more points than you actually received (case 3). In this case, your transfer choice will be automatically replaced by your total number of points. Example: You are not informed about your points and transfer 90 points to player B. In case that you only received 80 points, your transfer will be automatically reduced to 80 points.

You also need to give your estimates before you know which random number has been drawn. That is, at the time of your estimation, you do not know whether

1. you received 80 points.

2. you received 160 points.

This implies that you need to give two estimates for each of these cases: For each possible case you need to estimate whether you will be informed by the player B in your group, and how many out of 100 player B will inform their player A.

You will enter your choices into the software as follows:

[Screenshot (Decision)]

[Screenshot (Estimation)]

]

[Player B's specific instructions in the Manager condition:

Note that you as player B need to make your decision before you know which random number has been drawn. At the time of your decision you do not know whether player A

1. received 80 points.

2. received 160 points.

This implies that you have to make two decisions: For each of the two possible cases you have to decide whether you want to personally inform player A about his points.

You also need to give your estimates before you know which random number has been drawn. That is, you need to give an estimate for each of the following cases 
1. Player A received 80 points and has been informed by player B.

2. Player A received 160 points and has been informed by player B.

3. Player A is not informed about his points.

For each possible case you have to estimate how many points all players A will on average transfer to player B.

Note that player A cannot incur a loss if he chooses to transfer more points than he actually received (case 3 ). In this case, his transfer choice will be automatically replaced by his total number of points. Example: Player A is not informed about his points and transfers 90 points to player B. In case that player A only received 80 points, his transfer will be automatically reduced to 80 points.

You will enter your choices into the software as follows:

[Screenshot (Decision and Estimation)]

]

[Player A's specific instructions in the Automated \& manager condition:

Note that you as player A need to determine your transfer choice before you know which random number has been drawn and whether player $B$ informs you personally. At the time of your decision you do not know whether

1. you received 80 points.

2. you received 80 points and have been personally informed by player B.

3. you received 160 points.

4. you received 160 points and have been personally informed by player B.

This implies that you have to make four decisions: For each of the four possible cases you have to decide how many points you want to transfer to player B.

You also need to give your estimates before you know which random number has been drawn. That is, at the time of your estimation, you do not know whether

1. you received 80 points.

2. you received 160 points.

This implies that you need to give two estimates for each of these cases: For each possible case you need to estimate whether you will be informed by the player B in your group, and how many out of 100 player B will inform their player A.

You will enter your choices into the software as follows:

[Screenshot (Decision)]

[Screenshot (Estimation)] 
[Player B's specific instructions in the Automated \& manager condition:

Note that you as player B need to make your decision before you know which random number has been drawn. At the time of your decision you do not know whether player A

1. received 80 points.

2. received 160 points.

This implies that you have to make two decisions: For each of the two possible cases you have to decide whether you want to personally inform player A about his points.

You also need to give your estimates before you know which random number has been drawn. That is, you need to give an estimate for each of the following cases

1. Player A received 80 points.

2. Player A received 80 points and has also been personally informed by player B.

3. Player A received 160 points.

4. Player A received 160 points and has also been personally informed by player B.

For each possible case you have to estimate how many points all players A will on average transfer to player B.

You will enter your choices into the software as follows:

[Screenshot (Decision and Estimation)]

]

Following the specific parts of the instructions, players $A$ and $B$ received again identical versions of the instructions, as described in the following.

End of the experiment:

At the end of the experiment each player will learn the random draw for her group, as well as the relevant decision by player $\mathrm{A}$, and her final points.

[4 Practice Questions] 